\section{Molecular Characterization of Three Comercial Cultivars and a New Pollinator in Kiwifruit}

\author{
M.J. Prado, ${ }^{1}$ S. Romo,${ }^{2}$ and M. Novo \\ Dpto. Fisiología Vegetal, Escuela Politécnica Superior, Universidad de Santiago \\ de Compostela, Campus de Lugo, 27002 Lugo, Spain
}

M. Rey

Dpto. Biología Vegetaly Ciencia del Suelo, Facultad de Biología, Universidad de Vigo, Campus Universitario de Vigo, 36310 Vigo, Spain

M.T. Herrera and M.V. González

Dpto. Fisiología Vegetal, Escuela Politécnica Superior, Universidad de Santiago de Compostela, Campus de Lugo, 27002 Lugo, Spain

Aditional index words. Actinidia deliciosa, isozyme, molecular markers, randomly amplified polymorphic DNA, RAPD, amplified fragment-length polymorphism, AFLP, standard AFLP, modified AFLP

Abstract. We investigated the characterization of genotypes of Actinidia deliciosa (Chev.) Liang and Ferguson var. deliciosa by using isozymatic and molecular techniques [randomly amplified polymorphic DNA (RAPD), amplified fragment-length polymorphism (AFLP), standard AFLP, and modified AFLP]. Four genotypes were tested, the female cultivar 'Hayward', the traditional New Zealand pollinizers 'Matua' and 'Tomuri', and a new pollinizer named clone A selected in a breeding program in Spain. PGI and PGM were the only isozymes that allowed us to distinguish the kiwifruit genotypes, although the accessions of 'Matua' presented two different banding patterns for both isozymes. All three molecular markers differentiated between the genotypes of kiwifruit tested, although RAPD markers did not allow us to establish differences between accessions of 'Matua', while both standard and modified AFLP did. These results, along with those of isozymes, support the hypothesis that the male kiwifruit genotypes present in Europe belong to different clones. None of the markers used showed differences between accessions of 'Hayward', which would suggest that it is a uniform cultivar. On the other hand, clone A was a seedling derived from 'Hayward' and an unknown pollinizer. The results obtained using AFLP markers strongly suggest that 'Tomuri' may have been the male parent of clone A. A specific protocol for kiwifruit characterization based on a modified AFLP technique is also presented, that gave rise to the highest percentage of polymorphism while scoring the lowest number of bands. This, together with the technical features of modified AFLP markers, make them very useful for identifying propagated kiwifruit plant material in commercial nurseries.

Kiwifruit[Actinidiadeliciosa(Chev.)Liang and Ferguson] is a dioecious species which has been commercially planted in Europe since the early 1970s using plants from New Zealand.

Received for publication 7 July 2005. Accepted for publication 16 Oct. 2005. We would like to acknowledge the Ministerio de Educación y Cultura (Project CICYT 1FD97-1208) for their financial support, and the Xunta de Galicia for the award of a fellowship to M.J.Prado. We sincerely thank Roberto Astorga (ENCE Navia) and Juan Mesas and Ramiro Barcia Vieitez (Universidad de Santiago de Compostela) for making available their lab facilities, Guido Cipriani and Raffaelle Testolin for their critical contribution concerning publication and the analysis of results, and Mark Anderson for his linguistic assistance. We also thank Consejeria de Medio Rural y Pesca del Principado de Asturias (SERIDA) and KIWIATLANTICO S.A. for providing the plant material.

${ }^{1}$ Current address: Dpto. Biología Vegetal y Ciencia del Suelo, Facultad de Biología, Universidad de Vigo, Campus Universitario de Vigo, 36310 Vigo, Spain. To whom reprint requests should be addressed; e-mail chuspc@uvigo.es.

${ }^{2}$ M.J. Prado and S. Romo contributed equally to this work. plants, and those resulting from selection programs, which could then be protected as new cultivars in the future. Plant identification has traditionally been based on the observation and quantification of morphological, physiological or horticultural traits in order to distinguish species and varieties. This is a slow process due to the long juvenile periods and the necessity to determine the effects of environmental variation, from place to place and from season to season. New methodologies could accelerate and optimise identification. Thus, over the last 2 decades biochemical markers like isozyme and, more recently, molecular techniques, have arisen as powerful tools.

Isozymatic analyses have been used in numerous species for several applications, including plant breeding programmes. In particular they have been extensively used as genetic markers for the identification of cultivars of fruit trees. In kiwifruit, the development of procedures for the electrophoretic separation of isozymes started in the 1980s (Hirsch and Fortune, 1984, 1985; Li et al., 1986), although the poor resolution of bands restricted the usefulness of the technique. However, subsequent works allowed to obtain enzymatic systems useful for the identification of kiwifruit species and cultivars. Thus, Messina et al. (1991) reported the use of three isozymes (AAT, PGM, and PGI) for the identification of nine kiwifruit cultivars, while the study was extended by Testolin (1992) and Testolin and Ferguson (1997) who analyzed variability for sixteen isozyme systems in 20 taxa of Actinidia and inferred the phylogenetic relationships that existed between them. Huang et al. (1997) reported isozyme variation in 28 Actinidia taxa using 23 isozymatic systems and concluded that isozyme phenotype was effective for cultivar identification.

Molecular markers offer a significant advantage for genotype identification, in that fingerprinting may be done at any stage of development without being affected by variation induced by environmental factors, thereby offering a standardizable reference for the identification of any cultivar and to control its propagation (Wünsch and Hormaza, 2002). Randomly amplified polymorphic DNA (RAPD) markers (Williams et al., 1990) have been tested in Actinidia for the fingerprinting of different species and cultivars (Cipriani et al., 1996) and the study of phylogenetic relationships (Huang et al., 2002). This technique has also been used recently for the early selection of traits such as sex, which is linked to a marker but not expressed during the juvenile phase of growth. Harvey et al. (1997) reported two sex markers using RAPD markers in Actinidia chinensis, which were later converted by Gill et al. (1998) into sequence-characterized amplified regions (SCARs). More recently, Shirkot et al. (2002) analysed 34 random primers, of which eight identified sex in kiwifruit.

Amplified fragment-length polymorphism (AFLP) markers (Vos et al., 1995) have emerged as powerful molecular markers, since they reveal a high level of polymorphism and a great amount of markers per assay, which results in very high discrimination potential 
Table 1. Nucleotide sequence of the 10-mer K-labeled primers tested.

\begin{tabular}{llllll}
\hline Primer & Sequence $\left(5^{\prime}-3^{\prime}\right)$ & Primer & Sequence $\left(5^{\prime}-3^{\prime}\right)$ & Primer & Sequence $\left(5^{\prime}-3^{\prime}\right)$ \\
\hline KI-1 & GTCACCTGCT & KI-11 & GACACACTCC & KI-21 & CCCACCCTTG \\
KI-2 & GGCAGGCTGT & KI-12 & GGCATCGGCT & KI-22 & AGGCTGGGTG \\
KI-3 & CAGAGGTCCC & KI-13 & TTGGCGGCCT & KI-23 & TCGCCCAGTC \\
KI-4 & ACCGTTCCAG & KI-14 & ACGGGAGCAA & KI-24 & AACGTCGAGG \\
KI-5 & CTGATCGCGG & KI-15 & CAGGGGTGGA & KI-25 & CCACGTGCCA \\
KI-6 & CCACCACGAC & KI-16 & CTCGAACCCC & KI-26 & TGCGAGAGTC \\
KI-7 & ACACCGGAAC & KI-17 & TGAGGGGGAA & KI-27 & GGCTGCCAGT \\
KI-8 & CTCTGCGCGT & KI-18 & CATCGCCGCA & KI-28 & GACGCCTCCA \\
KI-9 & ACGGCAAGGA & KI-19 & AAGTCCGCTC & KI-29 & CCCGTGTAGG \\
KI-10 & CCTGGGTCCA & KI-20 & AAGCGACCTG & KI-30 & ACGGATCCTG \\
\hline
\end{tabular}

for gemplasm analysis. In kiwifruit, AFLPs were used with microsatellites to construct a genetic map, based on a cross between A. chinensis and A. callosa (Testolin et al., 2001). Recently a modification of the AFLP technique, combining the simplicity of the RAPD technique while maintaining higher reproducibility and analytical power, was published for rapid genetic characterization in plants (Ranamukhaarachchi et al., 2000). We have adapted for the first time this technique for the molecular characterization of kiwifruit genotypes as is customary in standard AFLP.

The objective of this study was the molecular characterization of the main kiwifruit commercial cultivars, as well as a new pollinizer named clone A. To achieve this goal, along with isozymes and RAPD markers, standard and a modified technique of AFLPs were used. In the case of clone $\mathrm{A}$, this characterization could be used for establishing its relationships with the commercial cultivars and also, together with morphological and agronomic features, for the protection of this new and interesting genotype which was selected in an specific program developed in northwestern Spain.

\section{Materials and Methods}

Plant material. All analyses were performed using plant material from adult kiwifruit plants (about 20 years old), growing in experimental orchards of Servicio Regional de Investigación y Desarrollo Agrario of Villaviciosa (Serida), located in the north of Spain (Asturias Princedom) and a commercial orchard of the Kiwi Atlantico S.A., a company located in northwestern Spain. Plant material from one 'Hayward' accession (HI) has been kindly supplied by Prof. Testolin (University of Udine, Italy).

Characterization was performed using the three main commercial genotypes, the female cultivar 'Hayward' (accessions HI, HA, and $\mathrm{HG}$ ) and the two traditional male cultivars, 'Matua'(accessions M, M3, M13, and M14) and 'Tomuri'( accession T) selected in New Zealand (Zhang and Thorp, 1986). Likewise, a fourth genotype was analyzed, clone A (accession A), a pollinizer selected for its good performance in the edafoclimatic conditions in the northwestern Spain (González et al., 1994).

Dormant harwood cuttings were collected and stored in a cool chamber $\left(4^{\circ} \mathrm{C}\right)$ for at least 2 months, then surface sterilized using $0.4 \%$ sodium azide and placed individually in glass vessels containing sterile distilled water. The cuttings were allowed to sprout in a growth chamber at $24 \pm 2{ }^{\circ} \mathrm{C}$ under photoperiod of 16 $\mathrm{h}$ light $\left(60 \mu \mathrm{mol} \cdot \mathrm{m}^{-2} \cdot \mathrm{s}^{-1}\right)$, and buds or young leaves were collected. In addition, young leaves from field-grown plants were collected and stored at $-80{ }^{\circ} \mathrm{C}$ until processed.

Isozyme analysis. For enzyme extraction, samples of about $20 \mathrm{mg}$ of fresh buds were crushed in Tris- $\mathrm{HCl} 0.1 \mathrm{M}, \mathrm{pH} 7.3$ containing $3 \%$ PVPP, $1 \% \beta$-2-mercaptoethanol, $0.12 \%$ EDTA, and $0.1 \%$ dithiothreitol. Extracts were absorbed onto Whatman paper (3MM) chromatography paper wicks and immediately loaded onto a gel. All steps were performed at $4{ }^{\circ} \mathrm{C}$ and following the recommendation by Testolin (1992).

Electrophoresis was carried out on $11 \%$ $(\mathrm{w} / \mathrm{v})$ horizontal starch gels containing $2 \%$ sucrose at $4{ }^{\circ} \mathrm{C}$. Voltage was selected at 150 to $250 \mathrm{~V} \cdot \mathrm{cm}^{-1}$ for Ashton and Poulik buffer, and at $50 \mathrm{~mA} \cdot \mathrm{cm}^{-1}$ for histidine buffer (Messina et al., 1991). When the samples were run for 80 $\mathrm{mm}$ from origin, electrophoresis was stopped and gels were cut horizontally to yield slices. Enzyme staining procedures were taken from Testolin (1992).

Fifteen enzyme systems were examined using the three indicated buffer systems above. These were aconitase (ACO, EC 4.2.1.3), alcohol dehydrogenase (ADH, EC 1.1.1.1), aspartate aminotransferase (AAT, EC 2.6.1.1), malic enzyme (ME, EC 1.1.1.40), esterase (EST, EC 3.1.1.1), phosphoglucomutase (PGM, EC 5.4.2.2), 6-phosphogluconate dehydrogenase (6PGD, EC 1.1.1.44), glucose-6-phosphate cose phosphate isomerase (PGI, EC 5.3.1.9), glutamate dehydrogenase (GDH, EC 1.4.1.3), isocitrate dehydrogenase (IDH, EC 1.1.1.42), malate dehydrogenase (MDH, EC 1.1.1.37), peroxidase (PX, EC 1.11.1.7), shikimate dehydrogenase (SKDH, EC 1.1.1.25), and uridine di-phosphoglucose pirophosphorilase(UGPP, EC 2.7.7.9)

RAPD markers. Extraction and purification of genomic DNA for RAPD markers was performed from fresh young expanding leaves $(100 \mathrm{mg})$ using the protocol of $\mathrm{Yu}$ and Pauls (1994) with the following modifications. Just before the tissue extraction, $0.1 \mathrm{M} \mathrm{B-2-}$ mercaptoethanol was added to the extraction buffer. In addition, the supernatant obtained after homogenization and centrifugation was washed with a volume of chloroform. Finally, an additional washing with $70 \%$ ethanol (about $600 \mu \mathrm{L}$ ) was carried out after DNA precipitation with two volumes of $100 \%$ ethanol. DNAyield was checked on a $0.8 \%$ agarose gel in TAE buffer and ethidium bromide stained.

PCR was performed in volumes of 25 $\mu \mathrm{L}$ containing $10 \mathrm{ng}$ DNA template, $2 \%$ dehydrogenase (G6PDH, EC 1.1.1.49), glu- formamide, $0.2 \mu \mathrm{M}$ primer, $200 \mu \mathrm{M}$ dNTPs, $2 \mathrm{mM} \mathrm{MgCl}_{2}$ and $1.5 \mathrm{U}$ of BIOTAQ DNA polymerase (Bioline). Amplification reactions were performed on a thermocycler (Techne) with the following temperature profile: $94{ }^{\circ} \mathrm{C}$ for $2 \mathrm{~min}, 35$ amplification cycles at $94{ }^{\circ} \mathrm{C}$ for $15 \mathrm{~s}, 34^{\circ} \mathrm{C}$ for $45 \mathrm{~s}$, and $72^{\circ} \mathrm{C}$ for $2 \mathrm{~min}$, and finally an extension cycle at $72{ }^{\circ} \mathrm{C}$ for 5 min. Amplification products were resolved in a $1.8 \%$ agarose gel with an electrophoresis run at $60 \mathrm{~V}$ for $3 \mathrm{~h}$. As molecular weight marker DNA of Lambda phage cut with EcoRI and HindIII was used.

In total, 68 primers of 10-bp-long arbitrary sequences, belonging to OPJ (except to OPJ6 and OPJ17) and OPM series (Operon Technologies Inc), or designed by us (primers $\mathrm{K}$, Table 1) and synthesized by Amersham Pharmacia Biotech, were tested.

AFLP markers. Extraction and purification of genomic DNA for AFLP markers was performed from young expanding leaves fresh or frozen at $-80{ }^{\circ} \mathrm{C}(1 \mathrm{~g})$ using the $\mathrm{CTAB}$ buffer according to the procedure described by Doyle and Doyle (1990). Polysaccharides were eliminated from the DNA suspension using 2-butoxyethanol following the procedure of Cipriani and Morgante (1993). DNA quantification was performed in the same way as for RAPD markers (see above).

AFLP markers were performed using the System I kit from Gibco BRL (Life Technologies) following the manufacturer's instructions but with some modifications in the concentrations used. Briefly, digestion was performed in $12.5 \mu \mathrm{L}$ of $40 \mathrm{ng} \cdot \mu \mathrm{L}^{-1} \mathrm{DNA}$. For ligation, $23.8 \mu \mathrm{L}$ of adaptor solution, and 1.2 $\mu \mathrm{L}$ (representing 1.2 U) of T4 DNA ligase were used. Preamplification was performed using $0.4 \mu \mathrm{L}$ of BIOTAQ DNA polymerase (Bioline) $(5 \mathrm{U} / \mu \mathrm{L})$. Preamplification reaction was performed using 25 cycles of $94{ }^{\circ} \mathrm{C}$ for $30 \mathrm{~s}, 56{ }^{\circ} \mathrm{C}$ for $60 \mathrm{~s}$, and $72{ }^{\circ} \mathrm{C}$ for $60 \mathrm{~s}$. Afterwards, each sample was diluted 25-fold. Selective amplification was carried out using $\left(\gamma^{33} \mathrm{P}\right.$-ATP)-labelled EcoRI primer and using the same quantity of BIOTAQ DNA polymerase as in the preamplification step. The protocol of amplification was 12 cycles of $94^{\circ} \mathrm{C}$ for 30 $\mathrm{s}, 65^{\circ} \mathrm{C}$ for $30 \mathrm{~s}$, and $72{ }^{\circ} \mathrm{C}$ for $60 \mathrm{~s}$, with the annealing temperature reduced by $0.7^{\circ} \mathrm{C}$ per cycle, then 23 cycles of $94^{\circ} \mathrm{C}$ for $30 \mathrm{~s}, 56^{\circ} \mathrm{C}$ for $30 \mathrm{~s}$, and $72{ }^{\circ} \mathrm{C}$ for $60 \mathrm{~s}$.

Amplification products and the molecular weight marker (100-bp ladder, Promega) were resolved in a $6 \%$ denaturing polyacrylamide gel (19 acrilamide: 1 bisacrilamide) containing $7 \mathrm{M}$ urea in TBE buffer and run at $58 \mathrm{~W}$ for $2 \mathrm{~h}$. After electrophoresis, the gel was dried on Whatman $3 \mathrm{MM}$ paper in a vacuum dryer at $80^{\circ} \mathrm{C}$ for $2 \mathrm{~h}$ and autoradiographed on X-ray film (Kodak) using standard procedures. Seven of the fifteen primer combinations previously published by Testolin et al. (2001) were tested.

Modified AFLP markers. DNA extraction was carried out following the protocol described for RAPD markers. Modified AFLP were carried out following the next protocol based on that described by Ranamukhaarachchi etal.(2000). Genomic DNA( $(0.5 \mu \mathrm{g})$ previously treated with RNAse $\left(1 \mu \mathrm{L}\right.$ of a $10 \mathrm{mg} \cdot \mathrm{mL}^{-1}$ 
solution) was digested using $5 \mathrm{U}$ of EcoRI enzyme. The digestion mixture $(35 \mu \mathrm{L})$ was incubated at $37^{\circ} \mathrm{C}$ for 6 to $12 \mathrm{~h}$, followed by the addition of $1 \mathrm{U}$ T4DNA ligase, $10 \times$ ligase buffer, ATP $10 \times$ and EcoRI adapter (to a concentration of $0.5 \mu \mathrm{M})$, making a total volume of $50 \mu \mathrm{L}$. This mixture was incubated overnight $(12 \mathrm{~h})$ at $16^{\circ} \mathrm{C}$. Following digestion/ligation, template DNA was purified by precipitation with two volumes of $100 \%$ ethanol and washing with $70 \%$ ethanol. Preamplification reaction conditions included 5 to $10 \mathrm{ng}$ template DNA, 1.66 U BIOTAQ DNA polymerase (Bioline), $1 \mu \mathrm{M}$ preselective primer, $200 \mu \mathrm{M}$ dNTPs, 2 $\mathrm{mM} \mathrm{MgCl}, 2 \%$ formamide, in a total volume of $25 \mu \mathrm{L}$. PCR conditions were $1 \mathrm{~min}$ at 94 ${ }^{\circ} \mathrm{C}$, followed by 28 cycles of $94{ }^{\circ} \mathrm{C}$ for 30 s, $60{ }^{\circ} \mathrm{C}$ for $1 \mathrm{~min}, 72^{\circ} \mathrm{C}$ for $1 \mathrm{~min}$, and finally 1 extension cycle at $72^{\circ} \mathrm{C}$ for $5 \mathrm{~min}$.

Selective amplification conditions included $1 \mu \mathrm{L}$ preamplification PCR, 1.66 U BIOTAQ DNA polymerase, $1 \mu \mathrm{M}$ selective primer, 200 $\mu \mathrm{M}$ dNTPs, $2 \mathrm{mM} \mathrm{MgCl}$, $2 \%$ formamide, in a total volume of $25 \mu \mathrm{L}$. PCR conditions were 2 min at $94{ }^{\circ} \mathrm{C}, 2$ cycles of $94{ }^{\circ} \mathrm{C}$ for $1 \mathrm{~s}, 64{ }^{\circ} \mathrm{C}$ for $30 \mathrm{~s}, 72{ }^{\circ} \mathrm{C}$ for $2 \mathrm{~min}, 6$ cycles in which the annealing temperature decreased $1{ }^{\circ} \mathrm{C}$ per cycle (touchdown), followed by 24 cycles of $94{ }^{\circ} \mathrm{C}$ for $1 \mathrm{~s}, 56^{\circ} \mathrm{C}$ for $30 \mathrm{~s}, 72^{\circ} \mathrm{C}$ for $2 \mathrm{~min}$, and a final extension cycle at $60^{\circ} \mathrm{C}$ for $30 \mathrm{~min}$. Amplification products were resolved in a 3\% agarose gel with an electrophoresis run at 60 $\mathrm{V}$ for about $12 \mathrm{~h}$.

Each preselective primer consisted of DNA sequences complementary to a major part of the adapter sequences containing a specific restriction site plus two arbitrarily assigned bases (18-mers) to the 3 ' end of the primer. Each selective primer consisted of the same DNA sequence of each preselective primer plus one arbitrarily assigned base (19-mers) to the 3 ' end of the primer (García-Mas et al., 2000).

Data analysis. PCR and electrophoresis were repeated at least twice for all primers and samples giving informative results in order to ascertain the reproducibility of the assay.

RAPD, standard and modified AFLP reproducible fragments were scored as present (1) or absent (0), and data were entered in a computer file as a binary matrix, one for each kind of marker. The matrices were then analyzed using the NTSYS-PC software version 2.10 (Rohlf, 1993). Similarity for qualitative data was computed using the Dice similarity index (Sneath and Sokal, 1973), and similarity estimates were analyzed by the UPGMA association method; the resulting clusters were expressed as dendrograms. In addition, cophenetic correlation coefficients were obtained using the Mantel test (Mantel, 1967) for construction of dendrograms.

\section{Results and Discussion}

Isozyme analysis. From the 15 enzymatic systems tested, 7 (AAT, ME, 6PGD, G-6PDH, GDH, PX, and UGPP) gave poor band resolution and/or were poorly stained and were discarded from the present study. Six of the remaining enzymatic systems (ACO, $\mathrm{ADH}$, EST, IDH, MDH, and SKDH) did not show variability in the genotypes (data not shown). Messina et al. (1991) also found three of these enzymes (ACO, MDH, and SKDH) to be invariable among kiwifruit genotypes, while the other three enzymes were either not tested (ADH and EST) or poorly resolved (IDH).

PGI and PGM were the only two enzymatic systems that presented variation in the genotypes (Fig. 1). For PGI (Fig. 1A), two zones of activity were found-being the slower the only polymorphic one. The phenotype we observed for the female cultivar 'Hayward' correspond with that found in an Italian clone by Messina et al. (1991), who observed a different banding pattern in several other Italian clones and standard ones from New Zealand. 'Tomuri' with five bands had the same phenotype in this study and Messina et al. (1991), supporting the allelic distribution described by Huang et al. (1997) for PGI. However, 'Matua' accessions had two banding patterns, with three and five bands (Fig. 1A), in contrast to the seven and nine bands reported by Messina et al. (1991) for Italian and New Zealand clones, respectively. Clone A showed banding patterns that were different from those of 'Matua' and 'Tomuri', although it presented three bands common to 'Tomuri', with two of them also present in 'Hayward'. Only one band was common to 'Matua'.

For PGM (Fig. 1B), two zones of activ- ity were found being polymorphic only the cathodal zone. In the present study, 'Matua' accessions once again presented two different banding patterns, both with three bands. One of these patterns was also present in 'Tomuri' and coincided with the pattern for 'Matua' standard clones from New Zealand, obtained by Messina et al. (1991). However, the other three-banded pattern was the same found for the female cultivar 'Hayward'. Interestingly, Messina et al. (1991) also found a 'Matua' phenotype fitting with 'Hayward', although with four bands. On the other hand, clone A was the only genotype to present four bands, sharing three of them with those of 'Matua' and 'Tomuri', and the fourth with 'Hayward'.

Therefore, results obtained for the different accessions of 'Matua' with PGI and PGM seem to confirm the hypothesis of Messina et al. (1991) based on previous morphological data of Testolin and Crivello (1987), that the male kiwifruit cultivars present in Europe belong to different clones. On the other hand, the authors cited above found that 'Hayward' is practically a uniform cultivar, whereas in the present work we found an isozyme pattern that was inconsistent with previous studies, which seems to indicate that different 'Hayward' clones may be in use within Europe.

In conclusion, isozyme analysis seems
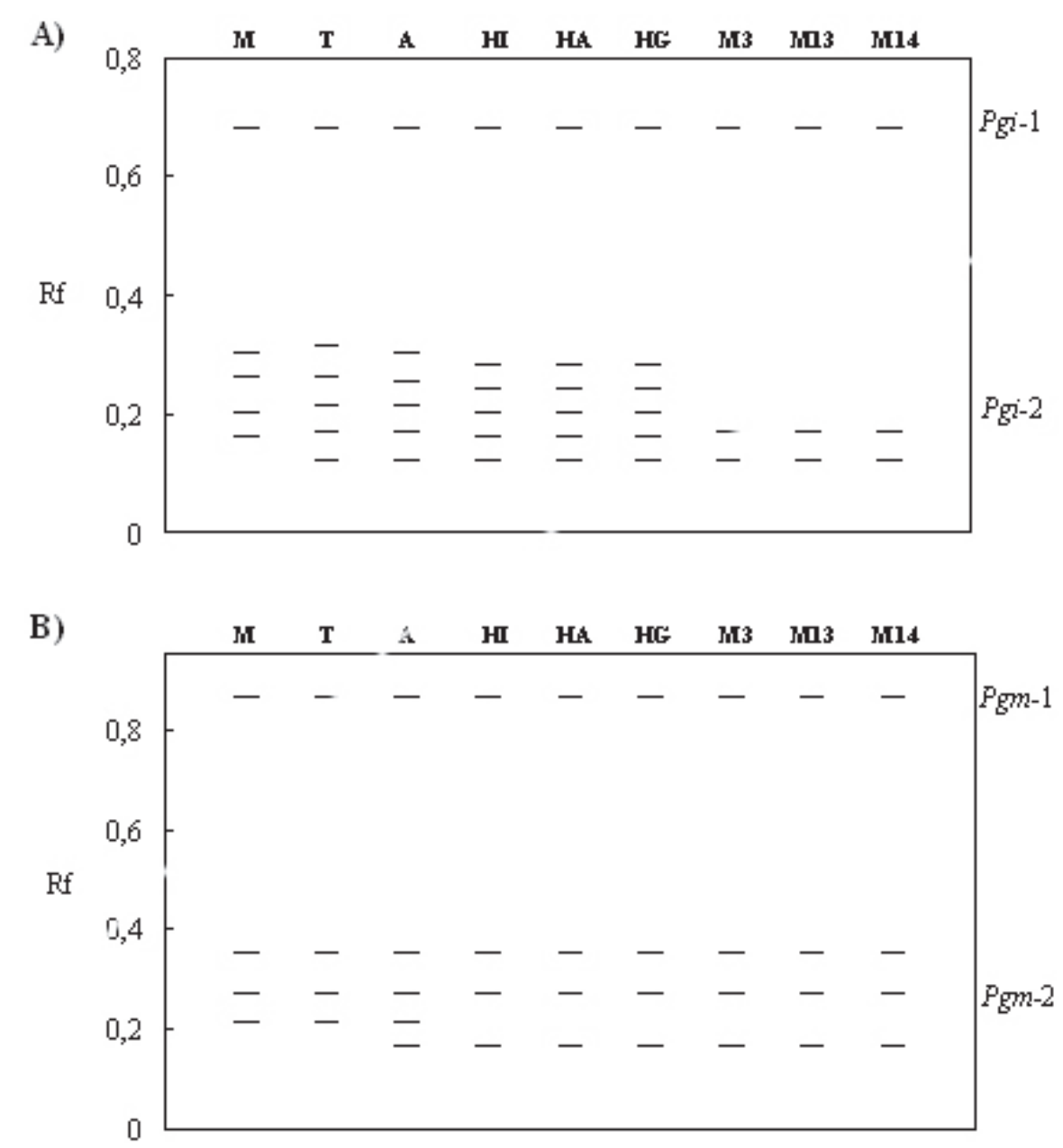

Fig. 1. Scheme of banding patterns of PGI (A) and PGM (B) enzyme systems obtained for the nine tested kiwifruit accessions. 
poorly reproducible, with different results obtained by different authors. As a possible explanation for the discrepancies it is important to remember that isozyme activities may be influenced by environmental conditions. In any case, from a practical point of view, this makes isozymes of little use for kiwifruit cultivar identification purposes.

Table 2. Analysis of informativeness of nine RAPD primers that gave polymorphisms among nine accessions of kiwifruit.

\begin{tabular}{lccc}
\hline $\begin{array}{l}\text { Polymorphic } \\
\text { primers }\end{array}$ & $\begin{array}{c}\text { Total } \\
\text { fragments } \\
\text { (no.) }\end{array}$ & $\begin{array}{c}\text { Polymorphic } \\
\text { fragments } \\
\text { (no.) }\end{array}$ & $\begin{array}{c}\text { Polymorphism } \\
(\%)\end{array}$ \\
\hline OPJ7 & 5 & $2(1 \mathrm{M})$ & 40 \\
OPJ13 & 9 & $6(1 \mathrm{~T}, 1 \mathrm{H})$ & 67 \\
K4 & 5 & 3 & 60 \\
K12 & 7 & 2 & 29 \\
K18 & 10 & $3(1 \mathrm{M}, 1 \mathrm{~A}, 1 \mathrm{~T})$ & 30 \\
K19 & 6 & $2(2 \mathrm{~T})$ & 33 \\
OPM6 & 7 & 2 & 29 \\
OPM11 & 8 & 6 & 75 \\
OPM12 & 7 & $2(1 \mathrm{M})$ & 29 \\
Total & 64 & 28 & 43 \\
\hline
\end{tabular}

${ }^{2}$ The number of polymorphic bands unique for a genotype, either by absence or presence, in brackets. Symbols represent each genotype tested: $\mathrm{M}$ = 'Matua'; $\mathrm{T}$ = 'Tomuri', A = clone A, H = 'Hayward'. ${ }^{2}$ The number of polymorphic bands unique for a genotype, either by absence or presence, in brackets. Symbols represent each genotype tested: $\mathrm{M}$ = 'Matua'; $\mathrm{T}$ = 'Tomuri', $\mathrm{A}$ = clone A, $\mathrm{H}$ = 'Hayward'.

Table 3. Analysis of informativeness of seven standard amplified fragment-length polymorphism (AFLP) primer combinations that gave polymorphisms among nine accessions of kiwifruit.

\begin{tabular}{llccc}
\hline $\begin{array}{l}\text { Primer } \\
\text { designation }\end{array}$ & $\begin{array}{c}\text { Selective } \\
\text { primer } \\
\text { combination }\end{array}$ & $\begin{array}{c}\text { Total } \\
\text { fragments } \\
(\text { no. })\end{array}$ & $\begin{array}{c}\text { Polymorphic } \\
\text { fragments } \\
(\text { no. })\end{array}$ & $\begin{array}{c}\text { Polymorphism } \\
(\%)\end{array}$ \\
\hline E1M1 & E-AAC+M-CAA & 95 & $49(2 \mathrm{~A}, 10 \mathrm{H})$ & 52 \\
E1M2 & E-AAC+M-CAC & 97 & $51(2 \mathrm{~A}, 11 \mathrm{H})$ & 53 \\
E5M6 & E-ACC+M-CTC & 105 & $73(2 \mathrm{M}, 1 \mathrm{~T}, 3 \mathrm{~A}, 15 \mathrm{H})$ & 70 \\
E7M8 & E-AGC+M-CTT & 107 & $38(5 \mathrm{~A}, 8 \mathrm{H})$ & 36 \\
E5M5 & E-ACC+M-CTA & 127 & $80(1 \mathrm{~T}, 6 \mathrm{~A}, 16 \mathrm{H})$ & 63 \\
E2M8 & E-ACG+M-CTT & 139 & $48(2 \mathrm{~T}, 8 \mathrm{H})$ & 35 \\
E3M5 & E-ACA+M-CTA & 114 & $55(6 \mathrm{~T}, 4 \mathrm{~A}, 20 \mathrm{H})$ & 48 \\
Total & & 784 & 394 & 50 \\
\hline
\end{tabular}

${ }^{2}$ The number of polymorphic bands unique for a genotype, either by absence or presence, in brackets. Symbols represent each genotype tested: $\mathrm{M}$ = 'Matua'; $\mathrm{T}$ = 'Tomuri', A = clone A, H = 'Hayward'.

Table 4. Analysis of informativeness of six modified amplified fragment-length polymorphism (AFLP) primer combinations which gave polymorphisms among nine accessions of kiwifruit.

\begin{tabular}{lcccc}
\hline $\begin{array}{l}\text { Primer } \\
\text { designation }\end{array}$ & $\begin{array}{c}\text { Selective } \\
\text { primer } \\
\text { combination }\end{array}$ & $\begin{array}{c}\text { Total } \\
\text { fragments } \\
\text { (no.) }\end{array}$ & $\begin{array}{c}\text { Polymorphic } \\
\text { fragments } \\
(\text { no. })\end{array}$ & $\begin{array}{c}\text { Polymorphism } \\
(\%)\end{array}$ \\
\hline $1 / 2$ & E-CAG & 15 & $11(2 \mathrm{~T}, 4 \mathrm{H})$ & 73 \\
$1 / 2 \mathrm{C}$ & E-CAT & 15 & $8(1 \mathrm{~T}, 1 \mathrm{H})$ & 53 \\
$2.5 / 5$ & E-TTA & 11 & $2(1 \mathrm{~T})$ & 18 \\
$6.5 / 10$ & E-GTG & 13 & $10(2 \mathrm{M}, 1 \mathrm{~A}, 1 \mathrm{H})$ & 77 \\
$10.5 / 11$ & E-ACA & 12 & $6(1 \mathrm{H})$ & 50 \\
$10.5 / 12$ & E-ACC & 10 & $6(1 \mathrm{~T}, 1 \mathrm{H})$ & 60 \\
Total & & 76 & 43 & 57 \\
\hline
\end{tabular}

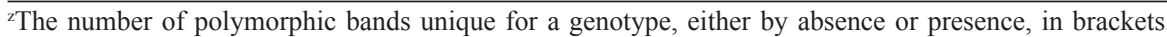
Symbols represent each genotype tested: $\mathrm{M}=$ 'Matua'; $\mathrm{T}$ = 'Tomuri', $\mathrm{A}=$ clone $\mathrm{A}, \mathrm{H}=$ 'Hayward'.

Table 5. A comparative analysis of kiwifruit genotypes using three diferent DNA markers; RAPD = randomly amplified polymorphic DNA, AFLP = amplified fragment-length polymorphism.

\begin{tabular}{lccc}
\hline Analysis & RAPD & $\begin{array}{c}\text { Standard } \\
\text { AFLP }\end{array}$ & $\begin{array}{c}\text { Modified } \\
\text { AFLP }\end{array}$ \\
\hline Total number of genotype-specific fragments & 9 & 122 & 16 \\
Average number of genotype-specific fragments per primer & 0.3 & 17.4 & 2.7 \\
Number of fragments unique to 'Matua' & 3 & 2 & 2 \\
Number of fragments unique to 'Tomuri' & 4 & 10 & 5 \\
Number of fragments unique to clone A & 1 & 22 & 1 \\
Number of fragments unique to female plants ('Hayward') & 1 & 88 & 8 \\
Number of fragments shared by 'Matua' and 'Tomuri' & 3 & 8 & 2 \\
Number of fragments shared by 'Matua' and clone A & 5 & 3 & 1 \\
Number of fragments shared by 'Tomuri' and clone A & 3 & 9 & 8 \\
\hline
\end{tabular}

polymorphism is high taking into account that other authors reporting higher polymorphism percentages in kiwifruit compared larger samples with more expected genetic variability (Cipriani etal., 1996; Huang etal., 2002; Shirkot et al., 2002).

In our study, the most informative primers were OPJ13 and OPM11, producing six polymorphic fragments each. OPJ13 showed the only polymorphic band unique to female plants, while OPM11 showed the highest percentage (75\%) of polymorphism. The less informative primers were K12, OPM6, and OPM12, which produced only two polymorphic fragments each with a percentage of polymorphism $<30 \%$, while K 18 with $30 \%$ informativeness produced the only unique band for clone A.

Standard AFLP. All seven standard AFLP primer combinations screened (Table 3 ) produced highly resolved bands (784 fragments), and polymorphic fragments (394 bands, 50\%) in kiwifruit. The number of scoreable bands ranged from 95 to 139 , and of polymorphic bands from 38 to 80 . These results were very similar to those obtained in grapevine (Cervera et al., 1998) and apricot (Hagen et al., 2002). The only work using standard AFLP in kiwifruit to date is that of Testolin et al. (2001) devoted to the construction of a linkage map from an interspecific cross $A$. chinensis $\times A$. callosa.

The most informative primer combinations were E5M6 and E5M5, producing 73 to 80 polymorphic fragments $(>60 \%)$, and simultaneously showing a great number of unique fragments (21 and 23 respectively). Most of these unique fragments belonged to the female genotype 'Hayward' (15 for E5M6 primers, and 16 for E5M5 primers). It is remarkable that E5M6 was the only primer combination that produced unique bands for the cultivar 'Matua'. The highest number of unique bands (30) was obtained with the E3M5 primers, 20 of them (67\%) unique to 'Hayward'. Other primer combinations had relatively low informativeness, such as E2M8 and E7M8 which had a low polymorphism percentage (about $35 \%$ ) and also displayed a low number of unique bands.

Modified AFLP analysis. All 6 modified AFLP selective primers screened (Table 4) produced highly resolved bands (76 fragments), once again, with all primers polymorphic (43 fragments, 57\%) in kiwifruit. They each gave 10 to 15 scoreable bands and 2 to 11 polymorphic fragments. The number of total bands observed was much lower than that obtained with the standard AFLP technique. These results were expected, since for modified AFLP only one restriction enzyme was used and electrophoresis was also run in an agarose gel according to Ranamukhaarachchi et al. (2000).

The most informative primers were $1 / 2$ and $6.5 / 10$, since they amplified 10 to 11 polymorphic fragments displaying a high polymorphism percentage $(>70 \%)$ and simultaneously the highest number of unique fragments (six and four respectively). Likewise, the primer $6.5 / 10$ was the only one that allowed us to obtain fragments unique to 'Matua' (two fragments) and to the novel male genotype clone A (one 
fragment). Other primers had dramatically low informativeness like primer $2.5 / 5(18 \%$

of polymorphism) with only one band unique to 'Tomuri'.
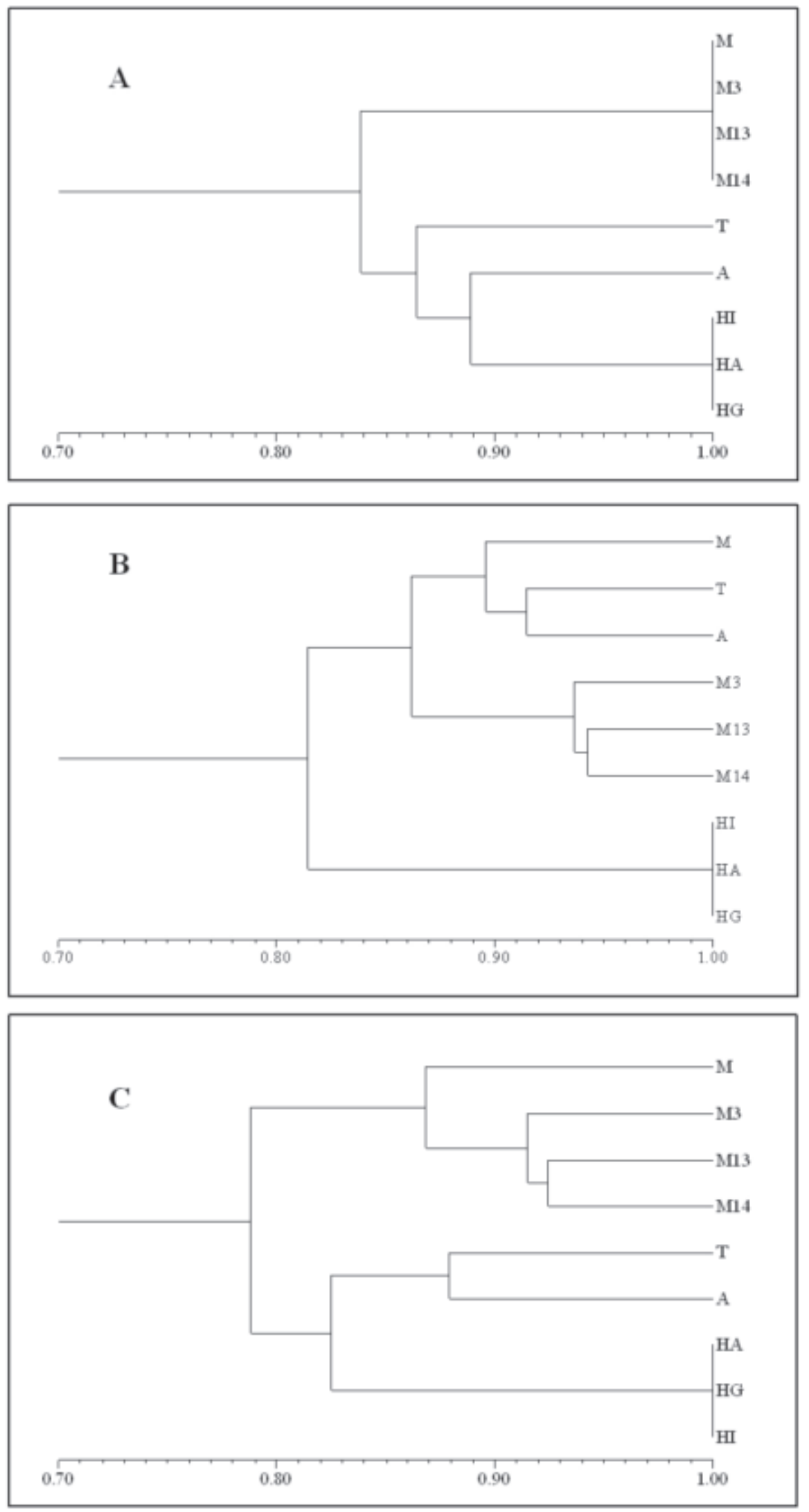

Fig. 2. Dendrograms of nine kiwifruit genotypes based on the Dice similarity index, obtained by (A) randomly amplified polymorphic DNA (RAPD) markers, (B) standard amplified fragment-length polymorphism (AFLP) markers, and (C) modified AFLP markers. Symbols represent each genotype tested: M, M3, M13, and M14 = accessions of 'Matua'; T = 'Tomuri'; A = clone A; HI, HA, HG = accessions of 'Hayward'.
Molecular comparison of kiwifruit genotypes. The comparative analysis of the kiwifruit genotypes used in the present study is summarized in the Table 5. In total, 28 polymorphic RAPD fragments were potentially useful for distinguishing genotypes being nine genotypespecific ( 0.3 on average). The greater numbers obtained were for 'Matua' and 'Tomuri' genotypes. On the other hand, a higher number of genotype-specific bands were detected using standard AFLP (122 bands, 17.4 on average) and modified AFLP (16 bands, 2.7 on average). In contrast with RAPD, using both AFLP techniques, the highest number of unique bands was obtained for 'Hayward'.

In a comparative analysis of polymorphic fragments shared by the male genotypes (Table 5) it was shown that 'Matua' and clone A shared five RAPD fragments, whereas both 'Matua' and 'Tomuri' or 'Tomuri' and clone A shared only three. However, the highest number of shared polymorphic AFLP fragments was between 'Tomuri' and clone A (nine standard AFLP fragments, and eight modified AFLP fragments).

Three dendrograms were constructed for RAPD (Fig. 2A), standard AFLP (Fig. 2B) and modified AFLP(Fig. 2C), with correlation coefficients ranging between 0.89 and 0.98 . These values indicate a good representation of the relationships among the genotypes, since Rohlf (1993) considered a value of $r=0.82$ to be significant.

The dendrogram constructed with standard AFLP data allowed us to distinguish one cluster including all male accessions, and another one for the female accessions. However, data from modified AFLP produced a dendrogram similar to that produced by the RAPD data in which there is a cluster for all 'Matua' accessions, and another for 'Hayward', 'Tomuri' and clone A. These two later dendrograms show a great similarity between 'Tomuri' and clone A. Taken together with the fact that clone A comes from a 'Hayward' seedling, it seems likely that 'Tomuri' was its male parent.

All three DNA markers allowed us to distinguish between the four genotypes of A. deliciosa var. deliciosa. However, RAPD markers did not allow us to establish differences among the four different accessions of the cultivar 'Matua', while both standard and modified AFLP did. On the other hand, none of the three markers showed differences between the three accessions of 'Hayward'. These results confirmed morphological and isozymatic data indicating that most kiwifruit male cultivars used in European orchards come from different clones. Messina et al. (1991) suggested that some seedlings had been propagated together with standard male cultivars in the early 1970s, when the demand for kiwifruit plants was increasing in Europe and in New Zealand. 'Hayward' does not seem to present this problem, although we have identified some mislabeled 'Hayward' clones in commercial orchards in northwestern Spain (data not shown).

In conclusion, this work underlines the need for a better identification of the kiwifruit plants distributed throughout European 
orchards, particularly in Spain. For this goal, it is evident the usefulness of AFLP markers for the characterization of Actinidia deliciosa genotypes since they produced higher levels of polymorphism than RAPD markers while testing fewer primers. In this study we also present a specific protocol for kiwifruit identification based on a modified AFLP technique, which gives rise to the highest percentage of polymorphism while scoring the lowest number of bands. This protocol could be the technique of choice in commercial nurseries in order to test the identity of the propagated or imported plant material since it is less expensive than the standard protocol, it does not require radioisotopes and generates markers using an agarose gel making easier the scoring of results.

\section{Literature Cited}

Cervera, M.T., J.A. Cabezas, J.C. Sancha, F. Martínez De Toda, and J.M. Martínez-Zapater. 1998. Application of AFLPs to the characterization of grapevine Vitis vinifera L. genetic resources. A case study with accessions from Rioja (Spain). Theor. Appl. Genet. 97:51-59.

Cipriani, G. and M. Morgante. 1993. Evidence of choroplast DNA variation in the genus Actinidia revealed by restriction analysis of PCR-amplified fragments. J. Genet. Breed. 47:319-326.

Cipriani, G., R. Di Bella, and R. Testolin. 1996. Screening RAPD primers for molecular taxonomy and cultivar fingerprinting in the genus Actinidia. Euphytica 90:169-174.

Doyle, J.J. and J.L. Doyle. 1990. Isolation of plant DNA from fresh tissue. Focus 12:13-15.

García-Mas, J., E. Grazcano, M.J.Aranzana, A. Monforte, M. Oliver, J. Ballester, M.A. Virual, and P. Arús. 2000. Marcadores de ADN: concepto, tipos y protocolos, p. 93-151. In: F. Nuez and J.M. Carrillo (eds.). Los marcadores genéticos en la mejora vegetal. Universidad Politécnica de Valencia, Valencia, Spain.

Gill, G.P., C.F. Harvey, R.C. Gardner, and L.G. Fraser. 1998. Development of sex-linked PCR markers for gender identification in Actinidia. Theor. Appl. Genet. 97:439-445.

González, M.V., M. Coque, and M. Herrero. 1994. Pollinator selection in kiwifruit (Actinidia deliciosa). J. Hort. Sci. 70:375-378.

Hagen, L.S., B. Khadari, P. Lambert, and J.M. Audergon. 2002. Genetic diversity in apricot by AFLP markers: Species and cultivars comparisons. Theor. Appl. Genet. 105:298-305.

Harvey, C.F., G.P. Gill, L.G. Fraser, and M.A. Mcneilage. 1997. Sex determination in Actinidia. I. Sex-linked markers and progeny sex ratio in diploid A. chinensis. Sex. Plant Reprod. 10:149-154.

Hirsch, A.M. and D. Fortune. 1984. Peroxidase activity and isoperoxidase composition in cultured stem tissue, callus and cell suspensions of Actinidia chinensis. Z. Pflanzenphysiol. 113:129-139.

Hirsch, A.M. and D. Fortune. 1985. Peroxidase as markers of organogenesis and dioecism in tissues of Actinidia chinensis L. Planchon cultured in vitro, p. 361-365. In: H. Greppin, C. Penel, and T. Gaspar (eds.). Molecular and physiological aspects of plant peroxidases. Univ. Geneve, Geneve.

Huang, H., F. Dane, H. Wang, Z. Jiang, R. Huang, and S. Wang. 1997. Isozyme inheritance variation in Actinidia. Heredity 78:328-336.

Huang, H., Z. Li, J. Li, T.L. Kubisiak, and D.R. Layne. 2002. Phylogenetic relationships in Actinidia as revealed by RAPD analysis. J. Amer. Soc. Hortc. Sci. 127: 759-766.

Li, C.Z., H.Y. Hua, and M.Z. Xu. 1986. A study on the application of isozyme analysis to the identification of sex in Actinidia chinensis. Plant Physiol. Commun. 2:12-13.

Mantel, N.A. 1967. The detection of disease clustering and a generalized regression approach. Cancer Res. 27:209-220.

Messina, R., R. Testolin, and M. Morgante. 1991. Isozymes for cultivar identification in kiwifruit. HortScience 26:899-902.

Ranamukhaarachchi, D.G., M.E. Kane, C.L. Guy, and K.B. Li. 2000. Modified AFLP technique for rapid genetic characterization in plants. BioTechniques 29:858-866.
Rohlf, F.J. 1993. NTSYSPC. Numerical taxonomy system. Exeter Software, New York.

Shirkot, P., D.R. Sharma, and T. Mohapatra. 2002. Molecular identification of sex in Actinidia deliciosa var. deliciosa by RAPD markers. Scientia Hort. 94:33-39.

Sneath, P.H.A. and R.R. Sokal. 1973. Numerical taxonomy. The principles and practice of numerical classification. Freeman, San Francisco, Calif.

Testolin, R. 1992. Starch electrophoresis of isozymes in the genus Actinidia. A laboratory manual. DSIR Techn. Rpt., Auckland.

Testolin, R. and V. Crivello. 1987. Il kiwi e il suo mondo (kiwifruit and its world). IRIPA-Quadrifoglio, Mestre-Venice.

Testolin, R. and A.R. Ferguson. 1997. Isozyme polymorphism in the genus Actinidia and the origin of the kiwifruit genome. Syst. Bot. 22:685-700.

Testolin, R., W.G. Huang, O. Lain, R. Messina, A. Vecchione, and G. Cipriani. 2001. A kiwifruit (Actinidia spp.) linkage map based on microsatellites and integrated with AFLP markers. Theor. Appl. Genet. 103:30-36.

Vos, P., R. Hogers, M. Bleeker, M. Reijans, T. Van de Lee, M. Hornes, A. Frijters, J. Pot, J. Peleman, M. Kuiper, and M. Zabeau. 1995. AFLP: A new technique for DNA fingerprinting. Nucleic Acids Res. 23:4407-4414.

Williams, J.G.K.,A.R. Kubelik, J.A. Rafalski, and S.V. Tingey. 1990. DNA polymorphisms amplified by arbitrary primers are useful as genetic markers. Nucleic Acids Res. 18:6531-6535.

Wünsch, A. and J.I. Hormaza. 2002. Cultivar identification and genetic fingerprinting of temperate fruit tree species using DNA markers. Euphytica 125:59-67.

Yu, K. and K.P. Pauls. 1994. Optimization ofDNA-extraction and $\mathrm{PCR}$ procedures for random amplified polymorphic DNA (RAPD) analysis in plants, $p$. 93-100. In: H.G. Griffin and A.M. Griffin (eds.). PCR technology: Current innovation. CRC Press Inc., Boca Raton, Fla.

Zhang, J. and T.G. Thorp. 1986. Morphology of nine pistillate and three staminate New Zealand clones of kiwifruit (Actinidia deliciosa (Chev.) Liang and Ferguson var. deliciosa). N.Z. J. Bot. 24:589-613. 